\title{
Risk of Transmission of Bovine Leukosis Virus (BLV) Using Semen from Seropositive Bulls in In Vitro Produced Embryos
}

\author{
Jacob Stewart, Marcello Rubessa, Kathryn M. Polkoff, Samantha Lotti, Matthew B. Wheeler
}

\begin{abstract}
Bovine Leukosis Virus (BLV) is a pathogen that affects the bovine immune system and leads to lymphosarcoma, leukemia, decreased milk production, and increased culling rates in cattle. The main transmission route between cattle is transfer of infected leukocytes from blood. Several farm practices, such as dehorning, rectal palpation, and vaccination can lead to pathogen transfer between animals that ultimately leads to high percentages of infected individuals within herds. This high percentage of infected animals restricts the trade of cattle on a global scale. Due to international trade laws and biosecurity concerns, semen from a BLV positive bulls is prohibited from sale between certain countries. The aim of this research was to study BLV transmission to embryos produced by in vitro fertilization (IVF) with semen from seropositive bulls. The first experiment examined the possible BLV transmission to embryos using seropositive bull semen in in vitro embryo production (IVP). The second experiment tested semen and medium for the presence of $B L V$ using two different protocols for sperm selection: 1) Percoll discontinuous gradients and 2) Swim-Up. The results showed no virus detection in the samples and the embryos produced did not show presence of the virus. The same results were observed in the second experiment where no viral presence was observed in the semen or media samples after sperm selection. In conclusion, these data indicate the use of BLV seropositive bull semen for the production of in vitro fertilized embryos posed no statistically significant risk of transmitting BLV to the embryos.

Index Terms-About four key words or phrases in alphabetical order, separated by commas.
\end{abstract}

\section{INTRODUCTION}

Many currently used embryo transfer methods in cattle originated in North America early in the 1970s [1, 2]. Initially, embryo transfer was used in animal production for the propagation of desirable phenotypes. Now, with a growing demand for genetically superior seedstock around the world,

*Corresponding Author:

these authors contributed equally to this paper

$\dagger$ Jacob Stewart, Department of Animal Sciences, University of Illinois, Urbana, IL, USA

†Marcello Rubessa, Institute for Genomic Biology, University of Illinois, Urbana, IL, USA, Tel. +1(217) 333-6189

Kathryn M. Polkoff, Department of Animal Sciences, University of Illinois, Urbana, IL, USA

Samantha Lotti, Department of Animal Sciences, University of Illinois, Urbana, IL, USA

*Matthew B. Wheeler, Department of Animal Sciences, Institute for Genomic Biology, University of Illinois, Urbana, IL, USA

This study was partially supported by Cooperative State Research, Education, and Extension Service, U.S. Department of Agriculture, under USDA Multi-state Project W-2171 and W-3171 through the College of Agriculture, Consumer and Environmental Sciences, and the Department of Animal Sciences at University of Illinois at Urbana-Champaign, USA it is common to use embryo transfer for the production of sires from exceptional cows and bulls using artificial insemination (AI) $[3,4]$. One of the most important issues in livestock breeding is the transmission of infectious diseases. This issue is so serious that it has slowed the growth and spread of embryo transfer technology worldwide. For example, several countries have implemented policies to stop the spread of certain diseases by prohibiting the importation of in vitro produced embryos derived from cows or bulls that are seropositive for certain infectious diseases. By barring these embryos from importation, countries lose potential economic gains from superior cattle genetics from other countries. A statistical analysis done in 2012 by International Embryo Transfer Society (IETS) representative Dr. George Perry found that disease status limited the export of IVF-derived embryos due to lack of research on disease transmission from IVF embryos. The Health and Safety Advisory Committee (HASAC) of IETS has categorized disease agents based on the risk of transmission through embryo transfer [5]: Category 1 is comprised of diseases and disease agents that have been shown to have a negligible risk of transmission with proper handling between collection and transfer. Bovine leukosis virus (BLV) is included in this category. BLV is a retrovirus that infects leukocytes of beef and dairy cattle.

Within the past 30 years, there has been a major increase of infected herds in the United States [6]. Recently, a study looked at the infection rate and found $38 \%$ of beef herds, $84 \%$ of all dairy herds, and $100 \%$ of large-scale dairy herds are infected with the virus [7]. In the USA, incidence of BLV infection has been estimated as high as $94.2 \%$ of dairy herds $[7,8]$. The high prevalence of BLV infection "suggests that the cost of testing and culling of seropositive animals may not be a cost effective method to control the disease" [7.]. Pelzer reported that as the incidence of BLV infection increased in a herd, the economic effects of culling infected animals may be cost prohibitive [9]. Furthermore, it has recently been reported that median and average incubation period to the clinical stage is 7 years and the fraction of animals developing clinical disease was only $1.4 \%$ [10]. This is an important piece of information because dairy cattle born in the USA since 1980 have an average of 3 parities and a productive herd life of $\sim 32$ months or a total age of $\sim 50$ months (4 years and 2 months) [11].

A major concern with BLV is the time it takes for clinical symptoms to appear. Clinical symptoms are typically observed four to five years after infection. Symptoms include swollen lymph nodes, weight loss, decreased milk production, anorexia, and limb paralysis. Roughly $29 \%$ of infected cattle 


\section{Risk of Transmission of Bovine Leukosis Virus (BLV) Using Semen from Seropositive Bulls in In Vitro Produced Embryos}

develop lymphocytosis and $<5 \%$ contract lymphosarcoma [8, 12]. Diagnosing BLV infected cattle can be done by simply testing serum for virus-specific antibodies [13]. But due to the characteristics of the virus, antibodies may not appear until roughly 6 months or more after infection.

The principal manner of transmission of BLV virus is through infected blood, milk, and to a lesser degree, semen. Common transmission outlets such as needles, palpation gloves, dehorning instruments, and other medical tools that are used without being properly sterilized, disinfected or cleaned allow for BLV to be transmitted [14]. The current cost of BLV testing can be deterrent for producers and therefore, infected animals typically go undiagnosed. The most effective way to slow and ultimately stop the spread of BLV within herds is to develop management protocols that include changing gloves and needles and thoroughly cleaning and disinfecting tools before and after each use [12]. Evermann et al. found that just $1 \mu 1$ of BLV-infected blood can infect an exposed animal [15]. Unfortunately, these common management practices have caused the spread of the virus in herds throughout the United States and the world.

Bovine leukosis virus has had and continues to have an adverse effect on the dissemination of high quality cattle genetics across the world. With increased biosecurity concerns, countries have become more stringent on import or export of animal products including semen, oocytes, and embryos without extensive medical screening of the donor animals. Many countries in Latin America, the European Union (EU) and individual countries like Australia and New Zealand have eradication programs and health restrictions that have led to negligible rates of BLV infection [16].

Several studies in the past have examined BLV transmission using seropositive bulls for AI and showed no detectable virus in the inseminated cow(s) $[17,18]$. Choi et al showed that AI companies using correct collection techniques, leukocyte microscopic evaluation, and a specific BLV PCR procedure could properly identify the active shedding of the virus from seropositive bulls used for AI [19]. In addition, field studies have not been able to show BLV infection after insemination of heifers via AI [20, 21]. With regard to ova and embryos, BLV was not isolated from 26 ova or 60 embryos obtained from $20 \mathrm{BLV}$ infected cows [22]. Hare et al. showed that in vivo-produced embryos from BLV-infected donor transferred to recipients produced 57 calves. Of these 57 calves and the recipients that calved them there was a zero incidence of BLV antibodies indicating no transmission of the virus [23]. The aim of the present study was to determine if there was BLV transmission to embryos produced by in vitro fertilization (IVF) with semen from seropositive bulls.

\section{MATERIAL AND METHODS}

A. Animals

Semen from three seropositive bulls and one seronegative bull, as the control, were used for these experiments. Bulls were tested prior to collection and confirmed by the bull stud using an ELISA and gp51-specific antibody (AGID) for BLV antibodies. Semen was collected, extended, and frozen according to CSS standard procedures at the bull stud.

Matured bovine COC were purchased from DeSoto Biosciences (Seymour, TN, USA). A preliminary study evaluated the percentage of BLV positive oocytes collected from the slaughterhouse using BLV specific PCR [24]. An internal control gene (tRep-137) was used to test the validity of the PCR. All of the 44 samples were positive for the tRep-137 gene and all of the 44 samples were negative for the BLV DNA sequence. This result was significant at $\mathrm{P}<$ 0.01 with a $C h i$-square statistic of 88 .

\section{B. Embryo Production}

Unless otherwise stated, all reagents were purchased from Sigma-Aldrich (USA). The in vitro fertilization (IVF) medium was Tyrode's modified medium without glucose and bovine serum albumin (BSA), supplemented with $5.3 \mathrm{SI} / \mathrm{mL}$ heparin, $30 \mu \mathrm{M}$ penicillamine, $15 \mu \mathrm{M}$ hypotaurine, $1 \mu \mathrm{M}$ epinephrine, and $1 \%$ bovine serum (BS)(Sigma \#B9433). The in vitro culture (IVC) medium consisted of Synthetic Oviduct Fluid (SOF) medium [25], with $30 \mu \mathrm{L} / \mathrm{mL}$ essential amino acids, $10 \mu \mathrm{L} / \mathrm{mL}$ non-essential amino acids, and $5 \% \mathrm{BS}$.

In vitro matured cumulus-oocyte-complexes (COCs) were washed and transferred, 20-30 per well, into $300 \mu \mathrm{L}$ of IVF medium covered with mineral oil. For each replicate, two straws of conventional frozen semen from each bull were thawed at $37{ }^{\circ} \mathrm{C}$ for $40 \mathrm{sec}$. The sample was processed via Percoll discontinuous gradient (45-80\%). The semen was centrifuged first at $300 \mathrm{x} \mathrm{g}$ for $25 \mathrm{~min}$. The pellet was then reconstituted in $2 \mathrm{ml}$ of IVF medium and centrifuged twice at 160 and $108 \mathrm{x} \mathrm{g}$ for $10 \mathrm{~min}$. After processing, pellets were diluted with IVF medium and added to the fertilization wells at the concentration of $1 \times 10^{6}$ sperm $/ \mathrm{mL}$. Gametes were co-incubated for $20 \mathrm{~h}$ at $39^{\circ} \mathrm{C}$, in $5 \% \mathrm{CO}_{2}$ in air, after which presumptive zygotes were vortexed for 2 min to remove cumulus cells in HEPES-TCM with $5 \% \mathrm{BSA}$, washed twice in the same medium, and transferred, 30-50 per well, into $400 \mu \mathrm{L}$ of SOF. Zygotes were incubated in a humidified mixture of $5 \% \mathrm{CO}_{2}, 6 \% \mathrm{O}_{2}$, and $88 \% \quad \mathrm{~N}_{2}$ in air at the temperature of $39{ }^{\circ} \mathrm{C}$. The percentages of cleaved embryos and embryos reaching blastocysts were determined at day 7 of culture (day $0=$ IVF day). The embryos were scored for quality on the basis of morphological criteria. Only Grade 1 and 2 blastocysts (Bl) were considered in the evaluation of the final embryo yield [26].

\section{Swim Up}

The sample of thawed semen was layered carefully under $1 \mathrm{ml}$ of equilibrated sperm-TALP (Tyrode's albumin lactate pyruvate) medium in a centrifuge tube. After loading, the tube was placed in incubator at $39^{\circ} \mathrm{C}$ for 1 hour. After incubation, $400 \mu \mathrm{L}$ of the upper fraction of TALP (containing the selected sperm) was collected, placed in a tube, and centrifuged for $10 \mathrm{~min}$ at $160 \mathrm{x} \mathrm{g}$ [27]. The pellet obtained was used for PCR.

\section{DNA Isolation}

Embryos were put into $10 \mu \mathrm{L}$ of PBS, frozen, and stored individually at $-80{ }^{\circ} \mathrm{C}$ until assay. Twenty $(20) \mu \mathrm{L}$ of lysis buffer containing $15 \mathrm{mM}$ Tris- $\mathrm{HCl} \mathrm{pH} 8.9,50 \mathrm{mM}$ $\mathrm{KCl}, 2.5 \mathrm{mM} \mathrm{MgCl}_{2}, 0.1 \%$ Triton X-100, and $150 \mathrm{~g} / \mathrm{mL}$ proteinase $\mathrm{K}$ were added to each tube. The tubes were incubated at $55{ }^{\circ} \mathrm{C}$ for $1 \mathrm{~h}$ and proteinase $\mathrm{K}$ was then inactivated by incubation at $90{ }^{\circ} \mathrm{C}$ for $10 \mathrm{~min}$ [28].The semen samples were collected in $0.5 \mathrm{ml}$ tubes and stored individually at $-80{ }^{\circ} \mathrm{C}$ until assay. The samples were added 
directly to the PCR reaction skipping the DNA extraction.

E. $\quad$ Nested Polymerase Chain Reaction (PCR)

The PCR primers were designed off of the sequences and methods previously reported by Frechner [29]. The primer sequences are described below:

\begin{tabular}{|c|c|}
\hline & \\
\hline BLV-env-1 & TCT-GTG-CCA-AGT-CTC-CCA-GAT-A \\
\hline $5032-5053$ & \\
\hline BLV-env-2 & AAC-AAC-AAC-CTC-TGG-GAA-GGG \\
\hline $5629-5608$ & \\
\hline BLV-env-3 & CCC-ACA-AGG-GCG-GCG-CCG-GTT-T \\
\hline $5099-5121$ & \\
\hline BLV-env-4 & GCG-AGG-CCG-GGT-CCA-GAG-CTG-G \\
\hline $5542-5521$ & \\
\hline
\end{tabular}

The BLV-env-1/BLV-env-2 PCR-product size is $598 \mathrm{bp}$. While the BLV-env-3/BLV-env-4 PCR-product size is $444 \mathrm{bp}$. The control sequence used was an autosomal gene btRep-137 [30, 31]. The sequence for that control gene is outlined below:

btRep-137

C1TATTTTCGGAACGCGGGAGAGAAGAG-3

btRep-137

C2TATTTTTGATTCCCTCCGTGCGGCGCTTA-3

The btRep-137 PCR product is $450 \mathrm{bp}$.

The reaction solutions were mixed and then aliquoted into separate reaction tubes. The sample DNA was split and added to each of two different reaction tubes, one containing the btRep-137 control primers and one containing the BLV primers. One negative control sample (double distilled $\mathrm{H}_{2} \mathrm{O}$ ) and one positive control sample (seropositive blood) were analyzed with the embryo DNA samples. Total volumes of mixtures were calculated by multiplying the indicated volumes by the total number of samples, including controls, plus $10 \%$ to allow for pipetting error. The first PCR performed used a $50 \mu \mathrm{l}$ reaction volume. For the first reaction, the assay was optimized to $5 \mu$ PCR buffer, $20 \mu$ DNA $(\sim 1$ $\mu \mathrm{g}$ of DNA), $1.25 \mu \mathrm{l}$ each of the env-specific primers BLV-env- 1 and BLV-env-2 (20 pmol/ $\mu \mathrm{l}), 0.15 \mathrm{dNTP}$ (each $25 \mathrm{mM}), 3 \mu \mathrm{MgCl} 2(25 \mathrm{mM})$, and $0.25 \mu \mathrm{l}$ Taq polymerase $(1.25 \mathrm{U})$. This reaction followed the temperature profile: denaturation for 2 minutes at $94^{\circ} \mathrm{C} ; 30$ cycles of 30 seconds at $95^{\circ} \mathrm{C}, 30$ seconds at $58^{\circ} \mathrm{C}$ and 60 seconds at $72^{\circ} \mathrm{C}$; followed by 4 minutes at $72^{\circ} \mathrm{C}$. The nested PCR was performed using a $50 \mu \mathrm{l}$ reaction volume. For all positive reactions, a second reaction was performed. The second assay used $3 \mu \mathrm{l} \mathrm{PCR}$ product of the first PCR, $5 \mu$ l PCR buffer, $1.25 \mu \mathrm{l}$ each of the env-specific primers BLV-env-3 and BLV-env-4 (20 $\mathrm{pmol} / \mu \mathrm{l}), 0.15 \mathrm{dNTP}$ (each $25 \mathrm{mM}$ ), $0.25 \mu \mathrm{l}$ Taq polymerase (1.25U), and $36.1 \mu \mathrm{l}$ of distilled $\mathrm{H}_{2} \mathrm{O}$. The reaction followed the temperature profile: denaturation for 2 minutes at $94^{\circ} \mathrm{C}$; 30 cycles of 30 seconds at $95^{\circ} \mathrm{C}, 30$ seconds at $58^{\circ} \mathrm{C}$, and 60 seconds at $72^{\circ} \mathrm{C}$; followed by 4 minutes at $72^{\circ} \mathrm{C}$.

\section{F. Gel Electrophoresis}

The PCR products were analyzed by agarose gel electrophoresis on $2 \%$ agarose gels using ethidium bromide as the DNA stain. A 100 bp DNA Ladder (Thermo Scientific $^{\mathrm{TM}}$ GeneRuler 100 bp DNA Ladder: FERSM0241) was used to assess the results of the amplification of the sample for each embryo tested. The gels were visualized using a computerized visualization system (Gene Genius Bio Imaging system) for band size determination (Figure 1).

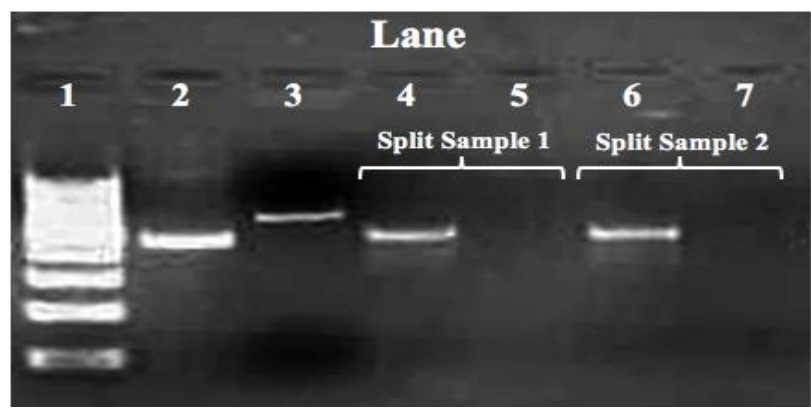

Figure 1: Representative agarose gel electrophoresis after PCR amplification of samples. Lane explanation, Lane 1; 100 kb DNA ladder, Lane 2; btRep-137 DNA control PCR product of $450 \mathrm{bp}$, Lane 3; BLV positive control PCR product of $598 \mathrm{bp}$, Lane 4; split sample 1 PCR product amplified using btRep-137 control primers, Lane 5; split sample 1 PCR product amplified using BLV-env-1/BLV-env-2 PCR primers, Lane 6; split sample 2 PCR products amplified using btRep-137 control primers, Lane7; split sample 1 PCR product amplified using BLV-env-1/BLV-env-2 PCR primers.

\section{G. Experiment 1}

The first experiment examined possible BLV transmission to embryos using seropositive bull semen in in vitro production (IVP). Four replicates were performed using each of the seropositive bulls and the control non-infected bull. Semen from each bull was used to fertilize 50 oocytes per replicate for a total number of 200 oocytes per bull. Using standard IVP protocols, seropositive Bull \#1 produced 48 embryos, Bull \#2 produced 41 embryos, Bull \#3 produced 46 embryos, and the control bull produced 66 embryos. All blastocysts produced were collected into $10 \mu \mathrm{l}$ of PBS, frozen, and stored individually at $-80^{\circ} \mathrm{C}$ until DNA extraction. The embryo DNA was extracted as previously described and tested using nested PCR.

\section{H. Experiment 2}

The second experiment tested semen and medium for the presence of BLV using two different protocols for sperm selection: 1) Percoll discontinued gradients and 2) Swim Up. Two 0.5cc straws of semen per bull were used for each replicate; they were combined and then divided into two treatments: Swim-Up and Percoll. Fractions from top, middle, and bottom were collected from each treatment (Figure 2.) and evaluated separately. Five replicates ( 3 infected and one non-infected control bull) were performed for a total of 120 samples evaluated. Five replicates X 2 semen straws per bull X 4 bulls $X 3$ sub-samples in the tube $=120$ samples. 


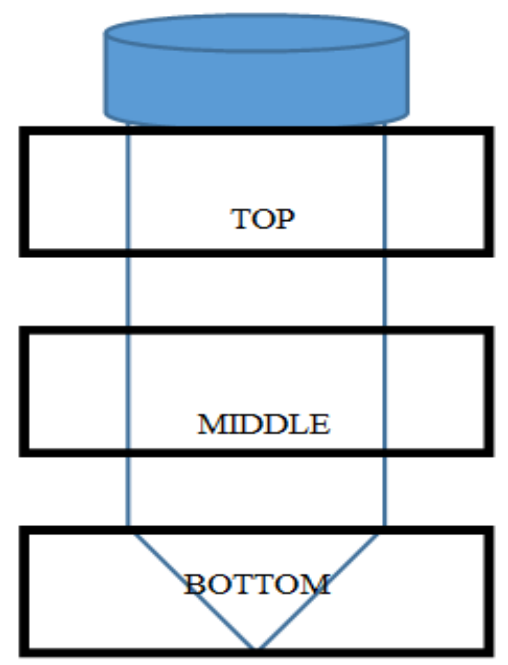

Figure 2. Representative diagram of the tube and the three subsamples evaluated after semen separation using the Swim-Up method.

\section{RESULTS}

The first experiment evaluated the potential infection of in vitro embryos produced with semen of seropositive bulls. No morphological differences were found between embryos produced with different bulls and no differences were found in blastocyst production rates. PCR evaluation of embryo DNA showed that BLV virus was not detected in any embryos tested (Table 1). The second experiment that evaluated viral presence in samples after semen processing also yielded negative results for all layers tested (bottom, middle, and top layers) in both discontinuous gradients and Swim-Up treatments (Table 2 and Table 3).

Table 1. A comparison of PCR positive results for embryos produced by BLV positive and control semen. The signals are from BLV or tRep-137 (housekeeping) genes as PCR markers.

\begin{tabular}{|l|l|l|l|}
\cline { 2 - 4 } \multicolumn{1}{c|}{} & BLV Positive Bulls & BLV Negative Bull & Marginal Row Totals \\
\hline tReV Positive PCR Product & 0 & 0 & 0 \\
\hline Marginal Column Totals & 135 & 66 & 201 \\
\hline
\end{tabular}

The Chi-square statistic is 201. No statistical difference ( $P<0.05)$ was observed between BLV positive bulls and the control bull for BLV infection.

Table 2. Semen (BLV positive and control) processed by Percoll. The products are from BLV or tRep-137 (housekeeping) genes used as PCR markers.

\begin{tabular}{|l|l|l|l|l|}
\hline Percoll & Top & Middle & Bottom & Marginal Row Totals \\
\hline BLV Positive PCR Product & 0 & 0 & 0 & 0 \\
\hline tRep-137 Positive PCR Product & 20 & 20 & 20 & 60 \\
\hline Marginal Column Totals & 20 & 20 & 20 & 60 \\
\hline
\end{tabular}

The Chi-square statistic is 60. No statistical difference ( $P<0.05)$ was observed between BLV positive bulls and the control bull for BLV infection

Table 3. Semen (BLV positive and control) processed by Swim Up. The products are from BLV or tRep-137 (housekeeping) genes as PCR markers

\begin{tabular}{|l|l|l|l|l|}
\hline Swim Up & Top & Middle & Bottom & Marginal Row Totals \\
\hline BLV Positive PCR Product & 0 & 0 & 0 & 0 \\
\hline tRep-137 Positive PCR Product & 20 & 20 & 20 & 60 \\
\hline Marginal Column Totals & 20 & 20 & 20 & 60 \\
\hline
\end{tabular}

The Chi-square statistic is 60. No statistical difference $(P>0.05)$ was observed between BLV positive bulls and the control bull for BLV infection

\section{DISCUSSION}

In the present studies we were unable to show the presence of BLV viral DNA in either the embryos produced from sperm from BLV seropositive bulls. We were also unable to detect the presence of BLV viral DNA in any of the samples that resulted from the washing of the sperm either by Swim-Up or discontinuous Percoll gradient treatment. It has previously been shown that in vivo-derived embryos exposed to BLV can be washed so that no infection occurs within the embryo [32]. This means that the BLV virus does not penetrate the intact zona pellucida. With this knowledge, the International Embryo Technology Society (IETS) developed a protocol that provides a series of washing steps in order to eliminate the BLV virus from the surface of the embryo [33]. Many studies have looked at infection in the semen and the possible risk of infecting the female inseminated with the semen. Nash et al. [34] found that bovine immunodeficiency virus (BIV), a retrovirus closely related to BLV, was found in seminal leukocytes, but no traces were found in the spermatozoa. Gradil et al. [35] also found no traces of the virus in the spermatozoa after artificially infecting bulls. Further, Kaja and Olson [18] found that transmission of the BLV virus did not occur when semen that was free of leukocytes when placed intraperitoneally in test sheep. Those in vivo results indicate that this type of virus does not affect the sperm cells themselves, and therefore embryos produced via IVF may not be infected. Bielanski et al. showed the possibility of producing embryos in vitro, with semen exposed to high concentrations of the BLV virus [32]. However, this paper showed that while there was no BLV viral DNA in 1) embryos from oocytes inseminated with BLV-spiked semen, 2) zona pellucida-intact embryos exposed to BLV after fertilization, 3) zona pellucida-free embryos exposed to BLV after fertilization, or 4) control embryos, sperm samples spiked with unusually high concentrations $\left(10^{5} \mathrm{TCID}_{50} / \mathrm{ml}\right)$ of virus were positive after Swim-Up separation. That experiment was performed using semen artificially infected (BLV-infected fetal lamb kidney cell line) with pharmacological concentrations of virus. Therefore, it was 
necessary (the present study) to test the ability of semen from a naturally infected bull to infect in vitro produced embryos. The present studies were designed to complement the studies previously cited, demonstrating that it is possible to obtain BLV-negative embryos using BLV seropositive bull semen. The present results (no virus detection in all samples) support the widespread results of previously published papers.[19, $23,35,36]$ The embryos produced in the present study did not show presence of the virus, in accordance other studies that evaluated in vitro $[32,33]$ and in vivo produced embryos $[23,36]$. However, in disagreement with Bielanskiet al., our results did not show positive semen samples after the Swim-Up [32] likely due to the absence of non-physiological titers of virus in the semen. Khamesipour et al. found BLV virus in $20 \%$ of frozen semen samples from bulls in commercial AI studs [37], but these results are inconsistent with our results and those of Choi et al. [19] who found the absence of BLV virus in the semen of seropositive bulls.

\section{CONCLUSIONS}

In conclusion, our data indicate the use of BLV seropositive bull semen for the production of in vitro fertilized embryos showed no statistically significant risk of infecting the embryos produced. Our results show that virus-free embryos can safely be produced from seropositive bulls. Our findings could lead to major changes in both IVF-derived embryos and also semen export. If semen companies could test high-demand BLV positive bulls for viral particles in the semen, virus-free semen could be exported. Further, IVF-derived embryos produced using semen from BLV seropositive bulls could be exported if the BLV virus was not present in the sample of that specific collection. Additional studies need to be performed with other bovine viruses (i.e. BVD, IBR) to determine if virus-free IVF embryos can be produced from semen from seropositive bulls for those organisms.

\section{Acknowledgements}

The authors would like to thank Dr. Luiz Fernando Nasser, BORN Animal Biotechnology, Panama City, Panama for helpful discussions on BLV transmission with IVF embryos and semen. The authors would also like to thank Ms. Molly Sermersheim for careful reading of the manuscript.

\section{DECLARATION OF INTERESTS}

The authors declare that there is no conflict of interest that could be perceived as prejudicing the impartiality of the research reported.

\section{REFERENCES}

[1] Betteridge KJ. An historical look at embryo transfer. J Reprod Fertil. 1981;62:1-13.

[2] Betteridge KJ. A history of farm animal embryo transfer and some associated techniques. Anim Reprod Sci. 2003;79:203-44.

[3] Keller DS, Teepker G. Effect of variability in response to superovulation on donor cow selection differentials in nucleus breeding schemes. J Dairy Sci. 1990;73:549-54.

[4] Mapletoft RJ, Hasler JF. Assisted reproductive technologies in cattle: a review. Rev Sci Tech. 2005;24:393-403.

[5] Stringfellow DA, Givens MD, Waldrop JG. Biosecurity issues associated with current and emerging embryo technologies. Reprod Fertil Dev. 2004;16:93-102.

[6] Buehring GC, Shen HM, Jensen HM, Choi KY, Sun D, Nuovo G. Bovine leukemia virus DNA in human breast tissue. Emerg Infect Dis. 2014;20:772-82.
[7] Anonymous. Bovine leukosis virus (BLV) on U.S. dairy operations, 2007.: USDA APHIS Veterinary Services, Center for Epidemiology and Animal Health; 2008.

[8] LaDronka RM, Ainsworth S, Wilkins MJ, Norby B, Byrem TM, Bartlett PC. Prevalence of Bovine Leukemia Virus Antibodies in US Dairy Cattle. Veterinary Medicine International. 2018;2018:8.

[9] Pelzer K. Economics of bovine leukemia virus infection. . Vet Clin N Am Food Anim Pract.13:129-41.

[10] Tsutsui T, Kobayashi S, Hayama Y, Yamamoto T. Fraction of bovine leukemia virus-infected dairy cattle developing enzootic bovine leukosis. Preventive Veterinary Medicine. 2016;124:96-101.

[11] Hare E, Norman HD, Wright JR. Survival Rates and Productive Herd Life of Dairy Cattle in the United States. J Dairy Sci 2006;89:3713-20

[12] Nagy DW. Overview of Bovine Leukosis. Merck Manual Veterinary Manual. Kenilworth, NJ, USA: 2018 Merck Sharp \& Dohme Corp., a subsidiary of Merck \& Co., Inc., Kenilworth, NJ, USA; 2018.

[13] Ott SL, Johnson R, Wells SJ. Association between bovine-leukosis virus seroprevalence and herd-level productivity on US dairy farms. Prev Vet Med. 2003;61:249-62.

[14] Rodríguez SM, Florins A, Gillet N, de Brogniez A, Sánchez-Alcaraz MT, Boxus M, et al. Preventive and therapeutic strategies for bovine leukemia virus: lessons for HTLV. Viruses. 2011;3:1210-48.

[15] Evermann JF, DiGiacomo RF, Ferrer JF, Parish SM. Transmission of bovine leukosis virus by blood inoculation. Am J Vet Res. 1986;47:1885-7.

[16] Anonymous. Enzootic Bovine Leukosis. Animal Disease: CABI; 2015.

[17] Monke DR. Noninfectivity of semen from bulls infected with bovine leukosis virus. J Am Vet Med Assoc. 1986;188:823-6.

[18] Kaja RW, Olson C. Non-infectivity of semen from bulls infected with bovine leukosis virus. Theriogenology. 1982;18:107-12.

[19] Choi KY, Monke D, Stott JL. Absence of bovine leukosis virus in semen of seropositive bulls. J Vet Diagn Invest. 2002;14:403-6.

[20] Thurmond MC, Carter RL, Burridge MJ. An investigation for seasonal trends in bovine leukemia virus infection. . Prev Vet Med 1983;1:115-23.

[21] Thurmond MC, Portier KM, Puhr DM, Burridge MJ. A prospective inves- tigation of bovine leukemia virus infection in young dairy cattle, using survival methods. . Am J Epidemiol 1983;117:621-31.

[22] Bouillant AMP, Ruckerbauer GM, Eaglesome MD, Samagh BS Singh EL, Hare WC, et al. Attempts to isolate bovine leukemia and bovine syncytial viruses from blood, uterine flush fluid, unfertilized ova and embryos from infected donor cattle. . Ann Rech Vet 1981;12:385.

[23] Hare WC, Mitchell D, Singh EL, Bouillant AM, Eaglesome MD, Ruckerbauer GM, et al. Embryo transfer in relation to bovine leukemia virus control and eradication. Can Vet J. 1985;26:231-4.

[24] Stewart J, Rubessa M, Polkoff KM, Lotti SN, Wheeler MB. Risk of transmission of bovine leukosis virus (BLV) using seropositive bulls for in vitro fertilization embryo production. . Reproduction, Fertility and Development. 2016;28:255-

[25] Tervit HR, Whittingham DG, Rowson LEA. Successful culture in vitro of sheep and cattle ova. Journal of Reproduction Fertility. 1972;3:493-7.

[26] Robertson I, Nelson R. Certification and identification of the embryo. Manual of the international embryo transfer society. 1998;9:103-16.

[27] Somfai T, Bodó S, Nagy S, Papp Á, Iváncsics J, Baranyai B, et al Effect of Swim up and Percoll Treatment on Viability and Acrosome Integrity of Frozen-thawed Bull Spermatozoa. Reproduction in Domestic Animals. 2002;37:285-90.

[28] Rubessa M, Boccia L, Campanile G, Longobardi V, Albarella S, Tateo A, et al. Effect of energy source during culture on in vitro embryo development, resistance to cryopreservation and sex ratio. Theriogenology. 2011;76:1347-55.

[29] Fechner H, Kurg A, Geue L, Blankenstein P, Mewes G, Ebner D, et al Evaluation of polymerase chain reaction (PCR) application in diagnosis of bovine leukaemia virus (BLV) infection in naturally infected cattle. Zentralbl Veterinarmed B. 1996;43:621-30.

[30] Alomar M, Tasiaux H, Remacle S, George F, Paul D, Donnay I. Kinetics of fertilization and development, and sex ratio of bovine embryos produced using the semen of different bulls. Animal Reproduction Science. 2008;107:48-61.

[31] Sattar A, Rubessa M, Di Francesco S, Longobardi V, Di Palo R, Zicarelli L, et al. The Influence of Gamete Co-incubation Length on the In Vitro Fertility and Sex Ratio of Bovine Bulls with Different Penetration Speed. Reproduction in Domestic Animals. 2011;46:1090-7. 
[32] Bielanski A, Maxwell P, Simard C. Effect of bovine leukaemia virus on embryonic development and association with in vitro fertilised embryos. Vet Rec. 2000;146:255-6.

[33] Stringfellow DA, Seidel SM, International Embryo Transfer S. Manual of the International Embryo Transfer Society : a procedural guide and general information for the use of embryo transfer technology emphasizing sanitary procedures. 3rd ed. ; rev. 1. ed. Savory, Ill. :: International Embryo Transfer Society; 2007.

[34] Nash JW, Hanson LA, St Cyr Coats K. Bovine immunodeficiency virus in stud bull semen. Am J Vet Res. 1995;56:760-3.

[35] Gradil CM, Watson RE, Renshaw RW, Gilbert RO, Dubovi EJ. Detection of bovine immunodeficiency virus DNA in the blood and semen of experimentally infected bulls. Vet Microbiol. 1999;70:21-31.

[36] DiGiacomo RF, Studer E, Evermann JF, Evered J. Embryo transfer and transmission of bovine leukosis virus in a dairy herd. J Am Vet Med Assoc. 1986;188:827-8.

[37] Khamesipour F, Doosti A, Shahraki AK, Goodarzi M. Molecular detection of Bovine Leukemia Virus (BLV) in the frozen semen samples of bulls used for artificial insemination in Iran. Research Opinions in Animal and Veterinary Science. 2013;3:412-6.

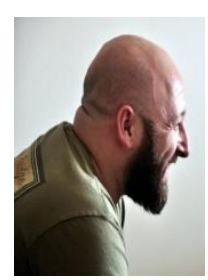

Marcello Rubessa obtained the Laurea Triennale (B.S.) and his Laurea Magistrale (M.S.), Biotechnology from the University of Naples. He obtained his Ph.D. degree from University of Naples (under the direction of Luigi Zicarelli). He is currently a Post Doctoral Researcher Associate at University of Illinois, Urbana. His areas of interest include embryo metabolism, improvement of IVP systems, stem cells and bone regeneration.

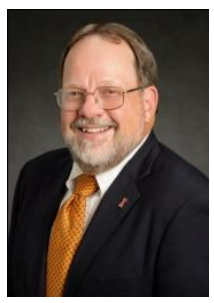

Matthew B. Wheeler obtained his B.S. degree from the University of California-Davis in 1977 and his M.S. degree from UC Davis in 1982. He obtained his Ph.D. degree from Colorado State University (under the direction of George E. Seidel) in 1986. He has been Professor at the University of Illinois of Illinois since 1989. His research interests included embryo biology, regenerative medicine, microfluidics, and gene expression during cell differentiation 